\title{
A LÓGICA INTERNA E O CONTEXTO DOS JOGOS TRADICIONAIS INDÍGENAS ORGANIZADOS NO ESTADO DO RIO GRANDE DO SUL ${ }^{1}$
}

Recebido em: 28/05/2015

Aceito em: 07/10/2015

Sabrine Damian Silva

João Francisco Magno Ribas

Universidade Federal de Santa Maria

Santa Maria - RS - Brasil

RESUMO: Este trabalho, caracterizado como uma pesquisa documental, analisou os Jogos Tradicionais indígenas descritos na pesquisa Diagnóstico dos Jogos Tradicionais do Campo e da Cidade no Estado do Rio Grande do Sul, tendo como objetivo identificar alguns elementos da lógica interna e do contexto desses jogos. A análise pautou-se na perspectiva teórica da Praxiologia Motriz, que tem se constituído em um dos relevantes conhecimentos da Educação Física, que dispõe de instrumentos de análise da estrutura e da dinâmica de funcionamento dos jogos e esportes. $\mathrm{O}$ aspecto mais marcante encontrado no presente estudo foi a possibilidade que esses jogos tradicionais proporcionam de uma convivência intergeracional, sendo os jogos protagonizados por pessoas de diferentes idades e gerações.

PALAVRAS CHAVE: Jogos Recreativos. Educação Física e Treinamento. Grupo Social. População Indígena.

\section{INTERNAL LOGIC AND THE CONTEXT OF INDIGENOUS TRADITIONAL GAMES ORGANIZED IN RIO GRANDE DO SUL STATE}

ABSTRACT: This work, characterized as a documentary research, analyzed the indigenous traditional games described in the research Diagnosis of Traditional Games Field and the City in the state of Rio Grande do Sul aiming to identify some elements of the internal logic and the context of those games. The analysis was marked in the theoretical perspective of Praxiology Motor, which has been set up in one of the relevant knowledge of Physical Education, which offers analytical tools of the structure and working of the games and sports. The most striking aspect found in this study was the possibility that these traditional games provide an intergenerational families, and those favored games for people of different ages and generations.

KEYWORDS: Games Recreational. Physical Education and Training. Social Group. Indigenous Poupulation .

\footnotetext{
${ }^{1}$ Pesquisa realizada com auxílio financeiro da CAPES, modalidade bolsa de mestrado.
} 


\section{Introdução}

A modernidade tem promovido um progressivo desuso dos jogos tradicionais, provocando um paulatino e contínuo abandono dos costumes antigos, relevando a substituição de práticas corporais importantes no passado por outras, principalmente no formato digital (MARIN et al., 2012). Diante desse cenário, o jogo tradicional se “tornou parte do nosso legado cultural, representando um patrimônio vivo que tem perdido força, expressão e notoriedade ao longo dos tempos" (DIAS; MENDES, 2010, p.55). Por ser uma cultura expressada em atos, uma cultura que revive nos gestos do corpo, abandonar esta prática significa um enfraquecimento cultural e a extinção de uma cultura (ELLOUMI; PARLEBAS, 2009). O jogo tradicional reflete a cultura de um povo, suas formas de organização e expressão, devendo ser registrado para que se possa preservar a identidade de cada povo, em cada momento histórico, para que as novas gerações possam conhecer e até mesmo praticar as manifestações corporais pertencentes à cultura dos seus antepassados.

No Brasil, nota-se pouco interesse e discussão acadêmica sobre o tema "Jogos Tradicionais", questão evidenciada pelo Grupo de Pesquisa em Lazer e Formação de Professores (GPELF) e pelo Grupo de Estudos Praxiológicos (GEP), ambos da Universidade Federal de Santa Maria (UFSM). Tais grupos possuem linhas de pesquisa em Jogos Tradicionais, atreladas a projetos de pesquisa e extensão, e identificaram, a partir de um levantamento realizado no portal do Diretório dos Grupos de Pesquisa no Brasil do CNPq (Conselho Nacional de Desenvolvimento Científico e Tecnológico), no segundo semestre do ano de 2014, que existe, além deles, apenas mais três grupos que abordam o tema como linhas de pesquisa no país. Fora do mundo acadêmico são 
encontradas, no contexto brasileiro, diversas Federações de Jogos Tradicionais, tais como a Bocha e o Bolão (LAVEGA et al., 2011).

No cenário internacional, encontramos várias associações em torno dos Jogos Tradicionais apresentadas no estudo de Lavega et al. (2011), podendo ser destacada a Associação Europeia de Jogos e Esportes Tradicionais (AEJDT) e a Associação Asiática de Jogos e Esportes Tradicionais (ATSGA), que conseguiram formar, em seus respectivos continentes, redes de instituições que trabalham com jogos tradicionais.

Mesmo estando essas duas Associações Continentais bem consolidadas, ainda havia lacunas referentes à dinamização das ações das diversas pessoas e instituições que se envolvem com o tema dos Jogos Tradicionais no mundo. Assim, foi fundada no ano de 2009, na cidade de Aranda de Duero, na Espanha, a Associação Internacional de Jogos e Esportes Tradicionais (ITSGA). Essa organização tem como finalidade representar, em nível mundial, os Jogos e Esportes Tradicionais, com o intuito de salvaguardar, estudar, trocar, promover e desenvolver a sua prática, para um melhor diálogo intercultural e uma melhor convivência da raça humana no mundo (ASOCIACIÓN INTERNACIONAL DE JUEGOS Y DEPORTES TRADICIONALES, 2009). Após esse importante feito em nível mundial, podemos destacar recentemente a criação da Associação Pan-americana de Jogos e Esportes Autóctones e Tradicionais (APJDAT), fundada em Honduras no ano 2013 para representar frente à ITSGA os Jogos e Esportes Autóctones e Tradicionais do Continente Americano.

Com base nesse cenário acadêmico e institucional, este estudo visa contribuir para o debate teórico dos jogos tradicionais no Brasil, área que, como já afirmamos, tem gerado pouca discussão e pouco debate científico no contexto brasileiro. 
Partimos do pressuposto de que o Jogo Tradicional constitui uma importante via para compreender um grupo social, suas formas de expressão e entender a sua dinâmica (PARLEBAS, 2003; CAILLOIS, 1990; HUIZINGA, 2008), uma vez que ele representa um elemento da cultura corporal, "resultado de conhecimentos socialmente produzidos e historicamente acumulados pela humanidade que necessitam ser retraçados e transmitidos" (SOARES et al., 1992, p. 39). Assim sendo, neste estudo reconhecemos inicialmente como jogo tradicional aquele "enraizado frequentemente em uma longa tradição cultural, que não tenha sido regulamentado por instituições oficiais" (PARLEBAS, 2001, p. 286). No jogo tradicional, como em qualquer outro jogo, o sistema de regras constitui a matriz fundamental. Entretanto, no jogo tradicional, fica a cargo da cultura local a transmissão de seus códigos e rituais (PARLEBAS, 2001).

A Praxiologia Motriz, conhecimento que surgiu na França na década de 1960 a partir da obra de Pierre Parlebas, oferece um conjunto de conceitos que otimizam a análise da estrutura e da dinâmica de funcionamento dos jogos tradicionais, ou melhor, da sua lógica interna. A lógica interna está diretamente ligada ao sistema de obrigações imposto pelas regras do jogo (PARLEBAS, 2001), isto é, dos limites a serem respeitados para que se possa participar do mesmo, dentro dos quais é gerada uma ordem ou lógica interna que deve ser interpretada, fazendo surgir as ações motrizes, que são o resultado observável e emergente da lógica interna de qualquer prática motriz (LAVEGA, 2004).

Como citado anteriormente, o GPELF vem investigando os jogos tradicionais e, no ano de 2010, o grupo desenvolveu a pesquisa Diagnóstico dos Jogos Tradicionais do Campo e da Cidade no Estado do Rio Grande do Sul ${ }^{2}$, com objetivo de realizar um

\footnotetext{
${ }^{2}$ Pesquisa financiada pelo Governo Federal (Ministério do Esporte/SNDEL/REDE CEDES).
} 
diagnóstico dos jogos tradicionais de distintos grupos sociais do campo e da cidade no Rio Grande do Sul. A pesquisa apresentou os jogos tradicionais e algumas características sociais e históricas dos grupos sociais pesquisados (alemães, portugueses, italianos e indígenas), entretanto, não foram realizados estudos e análises com base nos dados obtidos. Portanto, a partir das informações apresentadas na pesquisa do GPELF surge a questão central do presente estudo: Quais as características da lógica interna dos Jogos Tradicionais do grupo social indígena no Estado do Rio Grande do Sul e suas relações com o contexto?

Assim sendo, estabelecemos como objetivo principal deste estudo: analisar elementos da lógica interna e do contexto dos Jogos Tradicionais do grupo social indígena no Estado do Rio Grande do Sul, a partir dos dados descritos no Diagnóstico dos Jogos Tradicionais do Campo e da Cidade no Estado do Rio Grande do Sul.

\section{Encaminhamentos Metodológicos}

Consideramos o caminho metodológico como um modo planejado, no qual se leva em conta o objeto de pesquisa que se pretende esclarecer. Assim, nesse estudo, seguimos o caminho da Praxiologia Motriz, disciplina criada por Pierre Parlebas, que tem se constituído em um dos relevantes conhecimentos da Educação Física, que dispõe de instrumentos de análise da estrutura e da dinâmica de funcionamento dos jogos e esportes. Esse conhecimento foi utilizado para analisar os jogos tradicionais do grupo social indígena descritos na pesquisa Diagnóstico dos Jogos Tradicionais do Campo e da Cidade no Estado do Rio Grande do Sul, realizada pelo Grupo de Pesquisa em Lazer e Formação de Professores no ano de 2010, com objetivo de realizar um diagnóstico dos Jogos Tradicionais de distintos grupos sociais do campo e da cidade no Estado. 
A referida pesquisa, caracterizada como um estudo descritivo, foi realizada por meio de amostragem. Como a proposta do estudo foi analisar os jogos tradicionais do campo e da cidade de diferentes grupos sociais que compõem o Rio Grande do Sul, com suas marcas, diferenças e semelhanças presentes nos jogos tradicionais, foram investigados dois municípios de cada grupo social, um considerado rural e o outro com características urbanas. $\mathrm{O}$ recorte em torno dos diferentes grupos sociais e a definição dos municípios levou em conta os seguintes aspectos: proximidade com a Universidade Federal de Santa Maria (UFSM), local de trabalho dos pesquisadores; municípios rurais e urbanos; expressividade cultural e étnica; disponibilidade dos recursos financeiros, materiais e pessoais, ou seja, foram priorizados municípios que compõem o espaço de outros projetos de pesquisa e extensão do grupo GPELF/CEFD/UFSM, viabilizando as ações, devido a contatos e articulações já estabelecidos com instituições e profissionais da região. Nesse sentido, foram pesquisados os municípios constituídos predominantemente por descendentes de alemães, italianos, portugueses e uma reserva indígena, apresentados a seguir: Alemã - Agudo (Região Central), Nova Petrópolis (Serra Gaúcha) e Santa Cruz (Região Central); Italiana - São João do Polêsine e Ivorá (Região Central), e Bento Gonçalves (Serra Gaúcha); Portugueses - Pelotas e Rio Grande (Região Sul); Indígenas - Reserva do Guarita, Tenente Portela (Região Norte).

No presente estudo, detemo-nos na análise apenas dos jogos tradicionais do grupo social indígena. O nosso ponto de partida foi o projeto e o relatório da referida pesquisa. Esses materiais se encontram arquivados na sede do GPELF, no Centro de Educação Física e Desportos da UFSM, e foram disponibilizados pelos responsáveis para uso nesse estudo. Como principal fonte de análise, além desses materiais citados, 
utilizamos o livro originado da pesquisa do GPELF, intitulado "Jogo Tradicional e Cultura", publicado no ano de 2013 (MARIN; RIBAS, 2013).

A descrição dos jogos tradicionais no Mapeamento teve como orientação teórica a Praxiologia Motriz, sendo a estrutura de funcionamento do jogo tradicional ou esporte (lógica interna) descrita, utilizando-se os seguintes elementos: objetivo do jogo; materiais utilizados; descrição do jogo; número de jogadores e funções; espaço do jogo; sistema de pontuação; tempo de duração; finalização do jogo; premiação; e outras maneiras de jogar. Com relação ao contexto em que o jogo tradicional está inserido (lógica externa), a pesquisa apresentou elementos que pudessem evidenciar aspectos centrais desse espaço de inserção do jogo tradicional, consistindo em: modelo organizativo; instituição organizadora; membros da organização; tipo de público; reconhecimento institucional; jogadores; local; histórias ou palavras representativas do jogo; abrangência da atividade; dados históricos; e abrangência de inserção da atividade. Complementando a descrição da pesquisa, foram utilizadas também como critério as características de realização do jogo, sendo: motriz, aqueles que se concretizam na realização de ações que envolvem movimentos; e de mesa, para aqueles jogos que não são enfatizados pelo movimento. Desse modo, no total, foram descritos pelo Diagnóstico 13 jogos tradicionais do grupo social indígena.

O presente estudo se caracteriza como uma pesquisa documental pelo fato de utilizar como fonte de investigação dados originais, os quais ainda não receberam tratamento analítico (SÁ-SILVA; ALMEIDA; GUINDANI, 2009). Um documento, segundo Appolinário (2009), é:

Qualquer suporte que contenha informação registrada, formando uma unidade, que possa servir para consulta, estudo ou prova. Incluem-se nesse universo os impressos, os manuscritos, os registros audiovisuais e sonoros, as imagens, entre outros (APPOLINÁRIO, 2009, p.67). 
Muitos desses registros citados por Appolinário foram a base do estudo, como descrito anteriormente. A característica do documento de ser estático nos leva a concordar com Sá-Silva, Almeida e Guindani (2009, p. 8), ao afirmarem que “é impossível transformar um documento; é preciso aceitá-lo tal como ele se apresenta, às vezes, tão incompleto, parcial ou impreciso". Contudo, é fundamental que saibamos compor com as fontes documentais disponíveis, até mesmo com as mais pobres, pois, amiúde, elas são as únicas fontes que podem nos esclarecer sobre uma determinada situação (SÁ-SILVA; ALMEIDA; GUINDANI, 2009).

Foi utilizando os materiais disponíveis, bem como o livro resultante do Diagnóstico, que realizamos a classificação dos jogos tradicionais, fazendo uso do Sistema de Classificação proposto pela Praxiologia Motriz, o qual ordena as práticas motrizes segundo critérios de interação dos jogadores entre si e com o entorno físico.

O critério relativo às interações entre jogadores diz respeito a uma interação entre indivíduos, acompanhada de uma dedução constante de informação relativa ao comportamento dos diferentes participantes (PARLEBAS, 2003). Essa interação pode existir ou não, o que estabelece duas situações motrizes: situações psicomotrizes, quando não há interação com outros jogadores, ou seja, não há interação com companheiros nem adversários, o jogador atua sozinho, como, por exemplo, o lançamento de dardo; e situações sociomotrizes, que possuem em sua essência algum tipo de interação, podendo ser de três tipos: situações de cooperação ou comunicação motriz, quando o jogador tem que facilitar a leitura das suas ações para seu companheiro; situações de oposição ou contracomunicação motriz, quando o jogador tem que dificultar ao máximo a leitura das suas ações pelo seu adversário; e situações de 
cooperação-oposição, em que há interação de cooperação com companheiros e oposição com adversários, como, por exemplo, no jogo de taco.

A incerteza com o entorno físico é entendida pela informação que o sujeito deduz sobre o meio material a fim de organizar suas condutas motrizes (PARLEBAS, 2003). Refere-se às constantes leituras que o praticante tende a realizar do meio para que, assim, possa tomar suas decisões. De acordo com a presença ou ausência dessas leituras, temos duas situações: situações motrizes em um meio domesticado, quando o meio físico é conhecido do praticante, como quadras de vôlei e tênis, em que a leitura do meio é nula, pois ele é amplamente reconhecido pelo praticante; e situações motrizes em meio selvagem, que são atividades como surf e escalada, em que o praticante tem que realizar constante leitura do meio para adequar suas condutas motrizes. Neste segundo grupo, a "leitura das informações" provenientes do espaço é essencial para que o participante obtenha êxito na atividade.

Combinando os critérios relativos ao espaço com os critérios relativos à interação entre jogadores, a Praxiologia Motriz propõe oito categorias que compõem o Sistema de Classificação, que podem caracterizar qualquer jogo ou esporte. As categorias são representadas pelas iniciais relativas à presença de companheiros $(C)$, a presença de adversários (A) e a incerteza do meio físico (I). Assim, quando houver a ausência de algum dos critérios, este será representado com uma linha abaixo da letra correspondente. Na sequência são apresentadas as características de cada categoria.

CAI: Nessa categoria não há interação com companheiros nem com adversários, assim como também não há incerteza referente ao entorno físico. São exemplos de atividades os lançamentos e saltos do atletismo. 
CAI: Nesse grupo não há interação com outros participantes, porém há incerteza em relação ao entorno físico. As atividades realizadas individualmente na natureza, como a escalada e o surf, representam este grupo do sistema de classificação.

CAII: Esse grupo se refere às situações sociomotrizes, em que há apenas a interação entre companheiros, em um meio estável, padrão. Atividades como peteca e nado sincronizado ilustram este grupo.

CÁI: Essa categoria corresponde às atividades em que há interação entre companheiros, em um meio instável, como, por exemplo, corridas de orientação e alpinismo em equipe.

CAI: Essa categoria se refere às práticas em que há apenas a presença de adversários, realizada em um meio estável, característico de atividades como tênis individual, lutas e esgrima.

CAI: Nesse grupo há interação de oposição com o adversário realizada em um meio instável. Ilustram este grupo práticas como a corrida de mountain bike e o motocross.

CAII: Esse grupo corresponde às situações sociomotrizes em que há companheiros e adversários, realizadas em um meio estável. Nesta categoria se encontram práticas motrizes como cabo de guerra e futebol.

CAI: Nessa categoria há presença de companheiros e adversários interagindo em um meio instável, causador de incertezas, como as atividades de caça ao tesouro e corrida de caiaque.

Nesse Sistema de Classificação é importante destacar que todas as situações motrizes têm a mesma importância, independente de ser um jogo, esporte ou prática 
inventada (LAVEGA, 2008), e que cada grupo revela semelhanças estruturais (lógica interna).

O passo seguinte da pesquisa consistiu na análise de elementos referentes à lógica interna e ao contexto dos jogos tradicionais. Podemos descrever a lógica interna como a identidade de cada prática motriz, que está ligada ao sistema de regras do jogo, determinando comportamentos corporais característicos. A lógica interna abrange vários estratos do jogo, sendo impossível para a Praxiologia Motriz apresentar apenas um modelo que explique completamente a lógica interna. Para isso, faz-se necessária a combinação de representações, porém cada uma aportando o conhecimento de um campo concreto com uma estrutura matemática elementar (PARLEBAS, 2001).

Assim, de acordo com as informações disponíveis para o presente estudo, foi possível realizar a análise de apenas alguns elementos da lógica interna dos jogos tradicionais do grupo social indígena no Rio Grande do Sul, os quais são apresentados na sequência.

\section{RELAÇÃO ENTRE JOGADORES:}

\section{Lógica Interna}

1.1. Estrutura de interação: considera as interações de comunicação motriz que ocorrem no jogo.

1.1.1. Jogos solitários: são jogos sem comunicação motriz entre os jogadores (exemplo: saltos do atletismo).

1.1.2. Jogos cooperativos: há uma relação exclusiva de cooperação entre os jogadores (exemplo: paraquedas).

1.1.3. Todos contra todos: nesses jogos todos são adversários, cada jogador busca a vitória individualmente (exemplo: corridas de meio fundo em atletismo).

1.1.4. Duelos individuais (um contra um): um jogador deve vencer um adversário, podendo a contracomunicação ocorrer mediante contato corporal (exemplo: judô) ou através de algum objeto (exemplo: tênis individual).

1.1.5. Um contra todos: são jogos em que um jogador se opõe ao restante 
dos jogadores. Em algumas situações pode ocorrer de, ao conseguir o objetivo de capturar um adversário, os jogadores trocarem os papéis/funções (exemplos: pega-pega, esconde-esconde).

1.1.6. Duelos de equipe (equipe contra equipe): nessas situações, os jogadores têm claro quem são seus companheiros e quem são seus adversários (exemplo: futebol; taco).

1.1.7. Um contra todos - todos contra um: são jogos que iniciam com um jogador enfrentando o resto dos participantes e finaliza na situação de todos contra um. Os jogadores trocam de relações ou equipe durante o jogo (exemplo: pega-pega corrente).

1.1.8. Todos contra todos por equipe: diversas equipes de cooperação se enfrentam entre si (exemplo: batalhas a cavalo).

1.1.9. Paradoxal: são situações em que há ambivalência, ou seja, o jogador pode escolher continuamente entre a solidariedade e a rivalidade frente aos outros jogadores (exemplo: queimar ou passar).

1.2. Rede de comunicação motriz: apresenta as relações que se estabelecem entre os jogadores.

1.2.1. Rede de comunicação exclusiva ou rede de comunicação ambivalente:

1.2.1.1. Rede de comunicação exclusiva: é quando dois jogadores não podem ser simultaneamente companheiros e adversários. Cada jogador tem claro quem são seus companheiros e quem são seus adversários (exemplo: saltos; dez passes).

1.2.1.2. Rede de comunicação ambivalente: é quando qualquer jogador pode atuar a todo o momento como companheiro e/ou como adversário, caracterizando uma situação paradoxal (exemplo: queimar ou passar).

1.2.2. Rede de comunicação estável ou rede de comunicação instável:

1.2.2.1. Rede de comunicação estável: é aquela em que as relações de rivalidade e solidariedade não variam durante o transcurso do jogo. Cada jogador terá os mesmos companheiros e adversários do início ao fim do jogo (exemplo: natação, futebol).

1.2.2.2. Rede de comunicação instável: os jogadores variam as relações de cooperação e oposição durante o transcorrer do jogo, sendo que os companheiros que se têm ao início do jogo podem se tornar adversários no seu decorrer, assim como os adversários podem passar a ser companheiros (exemplo: caçador).

1.3. Rede de interações orientadas pelo objetivo do jogo: são comunicações 
e/ou contracomunicações que se realizam para pontuar no jogo, traça as vias pelas quais se podem alcançar os objetivos ludomotores do jogo.

1.3.1. Jogos com rede antagônica: as relações motrizes para ganhar o jogo se concretizam em ações de oposição, pois o objetivo do jogo está no espaço do adversário (exemplo: basquetebol).

1.3.2. Jogos com rede cooperativa: o êxito no jogo é alcançado por meio das relações motrizes estabelecidas pelas interações de cooperação (exemplo: 10 passes).

1.3.3. Jogos com rede mista (antagônica e cooperativa): combinam os dois tipos de interações anteriores para se chegar ao êxito no jogo, de forma que a ação de cooperação, sobretudo em forma de resgate, desfaz o resultado de uma ação de oposição (exemplo: queimar ou passar).

2. RELAÇÃO DO(S) JOGADOR(ES) COM O TEMPO: leva em consideração o modo como o jogo é finalizado.

2.1. Finalização por pontuação-limite: são jogos contabilizados por pontos, nos quais há uma pontuação-limite de finalização do jogo, em que o empate não é permitido (exemplo: o jogo de bocha, que finaliza com a equipe que primeiro alcançar 15 pontos).

2.2. Finalização por tempo-limite: os jogos são desenvolvidos em um tempolimite, em que o resultado da partida é estabelecido pela pontuação alcançada até o término do tempo regulamentar (exemplo: futebol).

2.3. Finalização por pontuação e tempo-limite: são jogos que permitem a contabilização mista, ou seja, terminam quando se chega à pontuação determinada ou se prolongam até o tempo preestabelecido (exemplo: golpe ippon no judô, que termina a luta antes do tempo preestabelecido).

2.4. Finalização da tarefa: os jogos finalizam quando se cumpre a tarefa estabelecida pelo jogo, ou seja, terminam com a finalização da tarefa. É um critério homogêneo de classificação dos jogadores, pois após a competição classifica os jogadores segundo o número de acertos ou pontuação (exemplo: arremesso de peso).

2.5. Finalização por causas externas: são jogos que não levam em conta acertos e erros, não somam pontos, típico de alguns jogos tradicionais, quando o jogo termina pela vontade dos jogadores, seja por cansaço, por estar escurecendo o dia ou qualquer outro motivo (exemplo: esconde-esconde; pega-pega).

3. RELAÇÃO DO(S) JOGADOR(ES) COM O(S) MATERIAL(IS): refere-se à presença ou ausência de objetos indispensáveis para a realização do jogo.

3.1. Jogos com material: são jogos que possuem algum tipo de objeto como elemento imprescindível para o seu desenvolvimento.

3.2. Jogos sem material: são jogos que não possuem nenhum tipo de objeto 
como elemento imprescindível para o seu desenvolvimento.

Em relação ao contexto (lógica externa) em que o jogo tradicional está inserido, foram escolhidos os seguintes elementos para análise nesse estudo:

\section{Lógica Externa}

1. PERFIL DOS PROTAGONISTAS DO JOGO: refere-se ao perfil dos jogadores que atuam diretamente no jogo.

1.1. Segundo a idade: a idade dos protagonistas foi disposta conforme está descrito na pesquisa Diagnóstico dos Jogos Tradicionais do Campo e da Cidade no Estado do Rio Grande do Sul.

1.2. Segundo o sexo: o sexo diz respeito à participação de homens e mulheres nos jogos.

1.2.1. Masculino: jogos praticados somente por homens.

1.2.2. Feminino: jogos praticados somente por mulheres.

1.2.3. Feminino e masculino: jogos praticados por homens e mulheres em partidas ou momentos diferentes.

1.2.4. Misto: jogos em que homens e mulheres participam conjuntamente.

2. LOCAIS DE JOGO: são os locais onde se desenvolve o jogo e as zonas específicas estabelecidas pelas regras.

2.1. Zona da localidade onde se joga: o jogo pode ser praticado em uma praça, rua, CTG, ou não possuir um local específico para a prática.

\subsection{Condição da zona onde se joga:}

2.2.1. Zona específica: é uma zona preparada especificamente para jogar (exemplo: ginásio; pista esportiva).

2.2.2. Zona já existente: é uma zona que já existe, adaptada para o jogo (exemplo: taco jogado na rua).

3. MATERIAIS: serão considerados para fins de análise apenas os materiais imprescindíveis para o desenvolvimento da atividade.

\subsection{Procedência dos objetos}

3.1.1. Produzido pelo homem: são objetos que sofreram uma transformação, que passaram por um processo até se constituírem no que são. O objeto pode ter origem em um ambiente do entorno domiciliar ou do espaço social cotidiano (exemplo: uma roda de um carro; uma cadeira).

3.1.2. Procedente do meio natural: são objetos extraídos da natureza e que não passaram por transformações, ou, então, foram transformações mínimas (exemplo: uma pedra; uma fruta da natureza; um osso de um animal). 


\subsection{Elaboração dos objetos:}

3.2.1. Elaboração artesanal: o processo de construção dos objetos é realizado por pessoas que seguem uma maneira própria de elaboração dos objetos, sendo que o objeto pode ser construído pelos próprios jogadores ou por outras pessoas.

3.2.1.1. Elaboração pelos próprios jogadores: são os próprios protagonistas do jogo que elaboram o objeto.

3.2.1.2. Elaboração por outros atores: a elaboração do objeto é realizada por outras pessoas (exemplo: um adulto que constrói um arco e flecha para as crianças fazerem jogos com alvo).

3.2.2. Materiais comprados/industrializados: são objetos comprados em lojas (exemplo: bola de futebol).

4. MODELO ORGANIZATIVO: trata do modo como estão organizados os jogos tradicionais. Essa organização será caracterizada no presente estudo segundo o modelo de instituição organizadora que os jogos seguem.

4.1 Instituição organizadora: é quem conduz ou o modelo de instituição que orienta a realização dos jogos.

4.1.1. Modelo esportivo: quando um jogo é organizado por uma federação esportiva e/ou segue o seu regulamento.

4.1.2. Modelo não esportivo: quando um jogo é organizado por uma associação cultural, escola, grupo de amigos etc., e não segue um regulamento específico de uma federação esportiva.

5. ESTADO EM QUE SE ENCONTRA O JOGO: é a situação de inserção social do jogo.

5.1. Jogo em fase de progressão: quando a prática do jogo está sendo resgatada.

5.2. Jogo em fase estável: prática regular do jogo.

5.3. Jogo em fase de regressão: quando se está deixando de praticar o jogo.

Após elencar, a partir da pesquisa do Diagnóstico, os elementos de lógica interna e lógica externa para análise nesse estudo, criamos uma planilha no programa Microsoft Excel 2010, na qual sistematizamos os jogos tradicionais indígenas de acordo com os elementos a serem analisados.

Vale destacar que nos jogos que possuíam informações incompletas e que não foram encontradas em nenhum dos documentos disponíveis para o estudo, o elemento 
ao qual se refere foi identificado na análise como "informação não encontrada"; isso devido à dimensão das atividades abranger muitas informações não contidas no estudo do Diagnóstico de forma clara, de maneira que se pudessem caracterizar plenamente os elementos que nos propusemos a analisar. Já os elementos que não foram passíveis de classificação, pelo fato de o jogo não se caracterizar por tal elemento, foram identificados na análise como "não classificado".

Como esse estudo se propõe a realizar uma análise praxiológica dos jogos tradicionais descritos no Diagnóstico, foram desconsiderados os brinquedos e os jogos de mesa, pois nessas atividades a "participação dos jogadores não é enfatizada pelo movimento" (MARIN; RIBAS, 2013, p. 30). A Praxiologia Motriz se propõe "a estudar a ação especificamente motriz, ou seja, [...] a que se concreta na intervenção do corpo" (PARLEBAS, 2001, p. 356). Assim, a cultura lúdica pesquisada nesse estudo foi de 8 jogos tradicionais do grupo social indígena.

\title{
Resultados e Discussão
}

O grupo social indígena é uma representação da grande diversidade cultural do nosso país, pois, conforme a Fundação Nacional de Saúde (FUNASA),

\begin{abstract}
a população indígena brasileira é estimada em, aproximadamente, 370.000 pessoas, pertencentes a cerca de 210 povos, falantes de mais de 170 línguas identificadas. Cada um destes povos tem sua própria maneira de entender e se organizar diante do mundo, que se manifesta nas suas diferentes formas de organização social, política, econômica e de relação com o meio ambiente e ocupação de seu território (FUNASA, 2002, p. 9).
\end{abstract}

No Estado do Rio Grande do Sul, a população indígena é de 19.634 indivíduos, pertencentes a três grupos indígenas: Guarani, Guarani Mbya e Kaigang - este último 
conta com a maior população, com 17.515 indivíduos (RIO GRANDE DO SUL, 2002; FUNASA, 2002).

O povoado indígena que integrou o estudo do Diagnóstico foi o Terra Indígena do Guarita, localizada entre os municípios de Tenente Portela, Redentora e Erval Seco, no noroeste do Estado. O contingente populacional da Terra Indígena do Guarita é de 5.109 Kaigangs e 259 Guaranis, que totalizam 5.368 indígenas, distribuídos em 13 setores populacionais. A sobrevivência das famílias Kaigangs vem da agricultura de subsistência, são poucas as famílias que praticam a agricultura para comercialização dos grãos. Também como fonte de renda dessa comunidade está o artesanato, reconhecido e comercializado em todo o Estado do Rio Grande do Sul e parte de Santa Catarina, principalmente em datas festivas, como a Páscoa e o Natal (RIBAS, 2013).

Da Terra Indígena do Guarita podemos destacar um importante trabalho que vem sendo realizado nas escolas da comunidade, que é o resgate histórico de jogos e brinquedos dos povos indígenas, assim como a inclusão desses jogos no conteúdo escolar (RIBAS, 2013). Também nessa comunidade a cultura indígena vem sendo resgatada através da realização de eventos, como o Evento das Manifestações Esportivas Indígenas do Guarita, realizado anualmente desde o ano de 2007; e os Jogos dos Povos Indígenas do RS, que têm por finalidade

promover à celebração através das expressões culturais tradicionais dos povos indígenas do RS, fomentando o resgate, a revitalização e principalmente a valorização da cultura indígena por meio do congraçamento entre os Povos Indígenas Kaingang e Guarani Mbya, incentivando a prática de suas manifestações esportivas e culturais bem como oportunizar um espaço de discussão e construção do conhecimento sobre, esporte, lazer, educação, saúde, trabalho, identidade e cultura (FUNDERGS, 2014, p. 1). 
Ações como essas se tornam importantes por ter sido encontrado um número muito reduzido de jogos tradicionais sendo preservados no seu contexto, conforme constatado no Diagnóstico.

Dos jogos tradicionais registrados no mapeamento, encontramos que $75 \%$ são realizados no Evento das Manifestações Esportivas Indígenas do Guarita (QUADRO 1). Desses, apenas um jogo - as lutas corporais - é praticado somente no evento. Os outros jogos, 62,5\%, são realizados tanto no Evento das Manifestações Esportivas Indígenas do Guarita quanto nas escolas. Também encontramos $25 \%$ de jogos que são realizados exclusivamente nas escolas.

Quadro 1 - Manifestação dos jogos tradicionais do grupo social indígena

\begin{tabular}{|c|c|c|}
\hline $\begin{array}{c}\text { MANIFESTAÇÃO } \\
\text { DOS JOGOS } \\
\text { PESQUISADOS } \\
\end{array}$ & $\begin{array}{l}\text { PERCENTUAL DE } \\
\text { OCORRÊNCIA }\end{array}$ & NOME DO JOGO \\
\hline Escola e evento & $62,5 \%$ & $\begin{array}{ll}\text { - } & \text { Arremesso de lança } \\
\text { - } & \text { Cabo de guerra } \\
\text { - } & \text { Bodoque } \\
\text { - } & \text { Arco e flecha } \\
\text { - } & \text { Corrida da tora }\end{array}$ \\
\hline Escola & $25 \%$ & $\begin{array}{l}\text { - Jogo da vareta de bambu } \\
\text { - Peteca }\end{array}$ \\
\hline Evento & $12,5 \%$ & - Lutas corporais \\
\hline
\end{tabular}

O modo como estão organizados os jogos tradicionais indígenas, ou seja, o seu modelo organizativo, mostra, em relação ao modelo de instituição que orienta a realização desses jogos tradicionais, que 100\% seguem um modelo não esportivo para sua prática, sendo organizados por professores indígenas e índios-chefes da Reserva do Guarita. Característica que diferencia esses jogos tradicionais do modelo esportivo seguido pelos esportes institucionalizados, em que cada modalidade esportiva é controlada e regida por suas federações e confederações. Esse modelo de organização institucional dos esportes floresce, conforme assinala Proni (2002), na sociedade 
industrial da segunda metade do século XIX, com a institucionalização das principais modalidades esportivas da Inglaterra. Esse autor também apresenta que o esporte moderno "nasce com a sociedade industrial e é inseparável de suas estruturas de funcionamento; evolui estruturando-se e organizando-se internamente de acordo com a evolução do capitalismo mundial; e assume forma e conteúdo que refletem essencialmente a ideologia burguesa" (PRONI, 2002, p. 37). Desse modo, encontramos como características explícitas das instituições que regem os esportes institucionalizados e, principalmente, as suas competições enquanto produto do capitalismo a mercadorização das práticas esportivas e a busca constante do lucro. Um exemplo do exposto é a instituição que dirige as associações de futebol, a Federação Internacional de Futebol (FIFA), que,

[...] ampliou seu domínio para além do chamado football association, tendo-se tornado responsável pela organização de outras competições, como as copas do mundo de futsal e de beach soccer. A entidade também passou a organizar a Copa do Mundo de Futebol Feminino, incluindo-se versões para meninas com idade abaixo de 20 e de 17 anos. A cereja do bolo, não é difícil imaginar, é chamada simplesmente de Copa do Mundo - para sermos precisos deveríamos dizer Copa do Mundo de Futebol Masculino ou, seguindo Blatter, Copa do Mundo da FIFA, pois de fato ela detém os direitos comerciais sobre a competição. A razão é um tanto óbvia: além de ser o evento campeão de audiência - algo estimado em 6 bilhões de espectadores - é, provavelmente, aquele que consegue amealhar maior retorno em termos de patrocínio e comercialização - antes mesmo de a bola rolar, a FIFA havia arrecadado algo em torno de R \$ 5,6 bilhões em 2010, sendo que todas as previsões são de aumento de receitas para 2014 (DAMO, 2011, p. 83).

Essa característica "informal” do modelo de organização dos jogos tradicionais indígenas também se manifesta nas categorias locais de jogo, em que encontramos como zonas da localidade onde são praticados os jogos: o campo de futebol da comunidade; a escola, suas dependências e seu entorno (QUADRO 2). Em 25\% dos jogos analisados não foram encontradas informações sobre a zona da localidade onde se 
joga. Em relação à condição dessas zonas utilizadas pelos indígenas, podemos dizer que são todas zonas já existentes, adaptadas para os diferentes jogos.

Quadro 2 - Zona da localidade onde são praticados os jogos tradicionais do grupo social indígena

\begin{tabular}{|l|c|l|}
\hline \multicolumn{1}{|c|}{$\begin{array}{c}\text { ZONA DA LOCALIDADE } \\
\text { ONDE SE JOGA }\end{array}$} & $\begin{array}{c}\text { PERCENTUAL DE } \\
\text { OCORRENCIA }\end{array}$ & NOME DO JOGO \\
\hline $\begin{array}{l}\text { Campo de futebol da } \\
\text { comunidade }\end{array}$ & $37,5 \%$ & $\begin{array}{l}\text { Arremesso de } \\
\text { lança } \\
\text { Cabo de guerra } \\
\text { Corrida da tora }\end{array}$ \\
\hline $\begin{array}{l}\text { Escola, suas dependências e seu } \\
\text { entorno }\end{array}$ & $37,5 \%$ & $\begin{array}{l}\text { Bodoque } \\
\bullet\end{array}$ \\
\hline Jnformação não encontrada & & $\begin{array}{l}\text { bambu } \\
\text { Peteca }\end{array}$ \\
\hline
\end{tabular}

Em relação aos materiais utilizados nos jogos tradicionais indígenas (QUADRO 3), localizamos, quanto à procedência dos materiais, que $62,5 \%$ dos jogos são realizados com objetos advindos do meio natural, $25 \%$ dos jogos são realizados com objetos produzidos pelo homem, e 12,5\% - que corresponde ao jogo lutas corporais - não são classificados quanto à procedência dos objetos, assim como também não são classificados quanto à sua elaboração, por não possuí-los. 
Quadro 3 - Relação do(s) jogador(es) com o(s) material(is), procedência e elaboração dos objetos nos jogos tradicionais do grupo social indígena

\begin{tabular}{|c|c|c|c|c|}
\hline \multicolumn{2}{|c|}{$\begin{array}{l}\text { LÓGICA } \\
\text { INTERNA }\end{array}$} & CÓGICA EXTERNA & \multirow[b]{2}{*}{$\begin{array}{c}\text { PORCENTUAL } \\
\text { DE } \\
\text { OCORRÊNCIA }\end{array}$} & \multirow[b]{2}{*}{$\begin{array}{l}\text { NOME DO } \\
\text { JOGO }\end{array}$} \\
\hline $\begin{array}{c}\text { Relação } \\
\text { do(s) } \\
\text { jogador(es) } \\
\text { com o(s) } \\
\text { material(is) }\end{array}$ & $\begin{array}{c}\text { Procedência } \\
\text { dos objetos }\end{array}$ & Elaboração dos objetos & & \\
\hline $\begin{array}{c}\text { Com } \\
\text { material }\end{array}$ & Meio natural & $\begin{array}{l}\text { Elaboração artesanal - } \\
\text { elaborado por outros } \\
\text { atores }\end{array}$ & $37,5 \%$ & $\begin{array}{l}\text { - Arremesso } \\
\text { de lança } \\
\text { - Arco e } \\
\text { flecha } \\
\text { - Corrida da } \\
\text { tora } \\
\end{array}$ \\
\hline $\begin{array}{c}\text { Com } \\
\text { material }\end{array}$ & Meio natural & $\begin{array}{l}\text { Elaboração artesanal - } \\
\text { elaborado pelos próprios } \\
\text { jogadores }\end{array}$ & $25 \%$ & $\begin{array}{l}\text { - Jogo da } \\
\text { vareta de } \\
\text { bambu } \\
\text { - Peteca }\end{array}$ \\
\hline $\begin{array}{c}\text { Com } \\
\text { material }\end{array}$ & $\begin{array}{l}\text { Produzido } \\
\text { pelo homem }\end{array}$ & $\begin{array}{l}\text { Material comprado/ } \\
\text { industrializado (bolinhas e } \\
\text { alvo); } \\
\text { Elaboração artesanal - } \\
\text { elaborado por outros } \\
\text { atores (bodoque) }\end{array}$ & $12,5 \%$ & - Bodoque \\
\hline $\begin{array}{l}\text { Com } \\
\text { material }\end{array}$ & $\begin{array}{l}\text { Produzido } \\
\text { pelo homem }\end{array}$ & $\begin{array}{l}\text { Material } \\
\text { comprado/industrializado }\end{array}$ & $12,5 \%$ & $\begin{array}{l}\text { - Cabo de } \\
\text { guerra }\end{array}$ \\
\hline Sem material & $\begin{array}{c}\text { Não } \\
\text { classificado }\end{array}$ & Não classificado & $12,5 \%$ & $\begin{array}{l}\text { - Lutas } \\
\text { corporais }\end{array}$ \\
\hline
\end{tabular}

Quanto à elaboração dos materiais utilizados nos jogos, encontramos, além do jogo lutas corporais, que não é classificado conforme mencionado, 37,5\% de jogos sendo elaborados artesanalmente por outras pessoas que não os próprios jogadores; $25 \%$ de jogos elaborados artesanalmente pelos próprios jogadores; $12,5 \%$ de jogos realizados com material comprado/industrializado; e 12,5\% de jogos que possuem mais de um objeto, sendo um comprado/industrializado e o outro elaborado artesanalmente, porém por outras pessoas que não os jogadores. Desse modo, localizamos que $87,5 \%$ dos jogos são realizados com algum tipo de objeto e que $12,5 \%$ dos jogos não possuem nenhum 
tipo de objeto como elemento imprescindível para o seu desenvolvimento. Destacamos, assim, que a maioria dos jogos indígenas são caracterizados por ter objetos necessários para o seu desenvolvimento e por estes terem sua procedência do meio natural, sendo sua elaboração realizada de maneira artesanal, seja pelos próprios jogadores, seja por outros atores. Vale lembrar que, como esses jogos estão inseridos no contexto escolar do grupo social indígena, essas características dos materiais podem ser exploradas pelos professores de maneira a direcionar para uma educação sustentável, em que:

[...] a busca de possíveis objetos de jogo, procedentes da natureza ou do entorno doméstico, unida ao processo de elaboração e construção personalizada destes elementos de jogo é uma extraordinária opção para deixar que os alunos sejam artesãos de seus próprios objetos de jogo, culminando essa experiência com a vivência de distintas situações de jogo com os materiais construídos (LAVEGA, 2006a, p. 61 - tradução nossa).

Uma experiência dessa natureza

[...] pode ensinar que é possível divertir-se e protagonizar aprendizagens inteligentes sem necessidade de dispor de excessivos recursos materiais. Por tanto, estas aprendizagens motoras estão unidas a pedagogia de temas ambientais tais como o desenvolvimento e o consumo sustentável, que se bem abordados podem educar valores (LAVEGA, 2006a, p. 69 - tradução nossa).

Uma educação com esses princípios possibilita, por meio da característica desses jogos tradicionais, discutir a lógica capitalista de consumo entrelaçada ao discurso publicitário que "reforça uma visão de mundo hegemônica, centrada no consumo de bens e serviços industrializados como resposta para as questões existenciais mais profundas" (ROCHA, 2011, p.163). A publicidade no campo esportivo incentiva o consumo, pela extensa cadeia de mercadorias que oferece, "tratando-se de mercado tão amplo e com tamanha variedade de produtos e diversidade de preços que se produzem 
segmentações ou classes a partir do acesso ou da restrição ao consumo" (DAMO, 2011, p. 73).

Em se tratando do perfil dos protagonistas do jogo, ou seja, os jogadores que atuam nos jogos tradicionais do grupo social indígena, encontramos grande heterogeneidade em relação à idade destes, jogos dos quais participam pessoas de todas as idades, pessoas acima de 5 anos, acima de 6 anos, acima de 14 anos e acima de 18 anos, conforme mostra o (QUADRO 4).

Quadro 4 - Idade dos protagonistas dos jogos tradicionais do grupo social indígena

\begin{tabular}{|c|c|c|}
\hline $\begin{array}{c}\text { IDADE DOS } \\
\text { PROTAGONISTAS }\end{array}$ & $\begin{array}{c}\text { PERCENTUAL } \\
\text { DE } \\
\text { OCORRENCIA }\end{array}$ & NOME DO JOGO \\
\hline Todas as idades & $37,5 \%$ & $\begin{array}{ll}\text { - } & \text { Arco e flecha } \\
\text { - } & \text { Bodoque } \\
\text { - } & \text { Cabo de guerra } \\
\end{array}$ \\
\hline Acima de 18 anos & $25 \%$ & $\begin{array}{l}\text { - Lutas corporais } \\
\text { - Corrida da tora }\end{array}$ \\
\hline Acima de 5 anos & $12,5 \%$ & $\begin{array}{l}\text { - Jogo da vareta de } \\
\text { bambu }\end{array}$ \\
\hline Acima de 6 anos & $12,5 \%$ & - $\quad$ Peteca \\
\hline Acima de 14 anos & $12,5 \%$ & - Arremesso de lança \\
\hline
\end{tabular}

Podemos notar que nos jogos tradicionais do grupo social indígena pessoas de várias faixas etárias interatuam nos mesmos jogos; essa característica pode ocorrer devido ao que é exposto no relato de um indígena, apresentado no livro "Brincar, Jogar, Viver: IX jogos dos povos indígenas":

[...] as crianças faz tudo que a gente faz [...], elas querem fazer flecha, corrida de tora, sempre que a gente faz uma corrida. Assim, em volta da aldeia, disputando sempre eles tão no meio. A gente arruma uma brincadeira, incentivando eles a participar da nossa cultura, em tudo eles vão (PINTO; GRANDO, 2011, p. 77).

Já outro indígena relata, também na obra de Pinto e Grando (2011, p.77), que "os anciões, os idosos, sempre estão presentes". Podemos observar a partir desses 
relatos que nos povos indígenas há um sentimento de cooperação, integração e alegria por vivenciar as atividades com pessoas de todas as idades. Essa intergeracionalidade proporcionada na prática dos jogos tradicionais do grupo social indígena não ocorre no mundo dos esportes, o qual possui categorias distintas, de acordo com a idade dos jogadores e sexo.

Em relação ao sexo dos protagonistas (QUADRO 5), percebemos que os jogos tradicionais indígenas, em que foram passíveis de identificar a informação sobre o sexo, apresentam-se manifestados de forma mista no ambiente escolar, ou seja, meninos e meninas participam conjuntamente da atividade. Um ponto julgado positivo, pois isso significa que não há distinção de sexo para a prática dos jogos nesta realidade escolar, contrário do que acontece em muitas escolas da atualidade, onde as práticas, geralmente esportivas, são separadas por sexo, ficando as meninas com o voleibol e os meninos com a prática do futebol.

Quadro 5 - Sexo dos protagonistas dos jogos tradicionais do grupo social indígena

\begin{tabular}{|l|c|l|}
\hline \multicolumn{1}{|c|}{$\begin{array}{c}\text { SEXO DOS } \\
\text { PROTAGONISTAS }\end{array}$} & $\begin{array}{c}\text { PERCENTUAL DE } \\
\text { OCORRENCIA }\end{array}$ & NOME DO JOGO \\
\hline $\begin{array}{l}\text { Misto (escola); } \\
\text { Masculino (evento) }\end{array}$ & $37,5 \%$ & $\begin{array}{l}\text { Arremesso de lança } \\
\text { Cabo de guerra } \\
\text { Bodoque }\end{array}$ \\
\hline $\begin{array}{l}\text { Informação não } \\
\text { encontrada }\end{array}$ & $37,5 \%$ & $\begin{array}{l}\text { - } \\
\text { - Arco e flecha } \\
\text { Corrida da tora }\end{array}$ \\
\hline Misto & $25 \%$ & $\begin{array}{l}\text { Jogo da vareta de } \\
\text { bambu } \\
\text { Peteca }\end{array}$ \\
\hline
\end{tabular}

Já os jogos tradicionais manifestados no evento da Reserva do Guarita que continham a informação sobre o sexo dos participantes demonstram que a sociedade indígena se organiza hierarquicamente entre os sexos, estratifica as pessoas, e isso se 
revela nos jogos, nos quais notamos ausência de jogos praticados somente por mulheres e modalidades em que homens e mulheres participam juntos.

Na obra de Pinto e Grando (2011), a já citada "Brincar, Jogar, Viver: IX jogos dos povos indígenas", que trata sobre a $9^{a}$ edição dos Jogos dos Povos Indígenas, são apresentas as atividades preferidas dos homens e mulheres indígenas por meio do relato dos próprios indígenas, em que encontramos indícios de uma divisão das atividades por sexo. Os relatos mostram que os homens gostam de pescar, jogar bola, puxar o cabo de guerra, flechar, caçar, corrida da tora, entre outras atividades, como a tradicional luta Uka Uka, que é uma luta tradicional dos povos indígenas do Xingu. As mulheres já gostam de realizar atividade como o artesanato - confeccionam brincos, colares e braceletes. Também gostam de jogar bola, puxar o cabo de guerra e dançar. O que chama atenção na fala dos indígenas é que grande parte deles relata ser o futebol a atividade preferida, tanto dos homens quanto das mulheres. Almeida (2008) aponta em seu estudo sobre os Jogos dos Povos Indígenas que o futebol é o único esporte praticado nesse evento, e por mais que este siga as normas do futebol de alto rendimento é notável que "foi apropriado pelas diferentes sociedades indígenas e adaptado à diversidade cultural das sociedades tradicionais" (ALMEIDA, 2008, p. 74).

Estudo realizado por Maestro (2006) sobre os jogos e esportes tradicionais em Aragón, região da Espanha, identificou a separação dos jogos por gênero, apontando jogos de mulheres e jogos de homens. Os jogos de mulheres, femininos, "estão determinados pelo papel que a mulher assumiu e desempenhou no mundo rural" (MAESTRO, 2006, p. 47 - tradução nossa), papel este de cuidados da casa, dos filhos e dos animais, sendo o lar o seu meio de vivências. Para as mulheres se relacionarem entre elas, reuniam-se em “carasoles”, locais abrigados das intempéries, que permitiam 
a elas se encontrar para conversar, costurar ou jogar bolos, sendo este jogo, por excelência, da mulher.

Os jogos de homens em Aragón estão muito ligados a bares e associados muitas vezes à existência de cantinas, onde se guardavam e alugavam bolas, assegurando, assim, o consumo dos jogadores na cantina. Também se praticavam nesses locais jogos de azar, jogos de pontaria e jogos que tivessem materiais e espaço para jogar. Entrar nesses espaços colocava o indivíduo em contato com apostas, que geralmente não eram de grande relevância econômica, pois, como em tudo no meio rural, o importante é relaxar o corpo, entreter-se, conversar e até mesmo jogar (MAESTRO, 2006).

Já Lavega (2006b, p.119), em seu estudo sobre os jogos e esportes tradicionais catalães, apresenta que nestes predominam jogos com grupos masculinos (41\%), seguidos de jogos com grupos mistos, onde homens e mulheres jogam juntos. São identificados, numa porcentagem inferior, jogos em que homens e mulheres jogam por separado $(18 \%)$ e jogos exclusivamente de mulheres $(1,5 \%)$.

No que tange à estrutura de interação entre os jogadores (QUADRO 6), encontramos: jogos solitários, aqueles sem comunicação motriz entre os jogadores; jogos cooperativos, em que há uma relação exclusiva de cooperação entre os jogadores; duelos de equipe, ou seja, duas equipes que se enfrentam, tendo os jogadores a definição de quem são seus companheiros e quem são seus adversários; e duelos individuais, nos quais um jogador enfrenta o outro em uma relação de oposição.

Quadro 6 - Estrutura de interação dos jogos tradicionais do grupo social indígena

\begin{tabular}{|c|c|c|}
\hline $\begin{array}{l}\text { ESTRUTURA DE } \\
\text { INTERAÇÃO }\end{array}$ & $\begin{array}{c}\text { PERCENTUAL DE } \\
\text { OCORRÊNCIA } \\
\end{array}$ & NOME DO JOGO \\
\hline Jogos solitários & $50 \%$ & $\begin{array}{l}\text { - Arremesso de lança } \\
\text { - } \text { Bodoque } \\
\text { - Arco e flecha } \\
\text { - Jogo da vareta de bambu }\end{array}$ \\
\hline
\end{tabular}




\begin{tabular}{|l|c|l|}
\hline Jogos cooperativos & $25 \%$ & $\begin{array}{l}\bullet \text { Peteca } \\
\text { - Corrida da tora }\end{array}$ \\
\hline Duelos de equipe & $12,5 \%$ & $\bullet$ Cabo de guerra \\
\hline Duelos individuais & $12,5 \%$ & $\bullet$ Lutas corporais \\
\hline
\end{tabular}

A rede de comunicação motriz de todos esses jogos é caracterizada por ser exclusiva e estável, ou seja, os jogadores sabem claramente quem são seus companheiros e adversários e mantêm essa relação do início ao fim do jogo. Resultado idêntico ao encontrado em todos os esportes e jogos motores tradicionais canários catalogados por Hernández et al. (2007). Segundo esses autores, a característica de evitar a ambiguidade nos jogos é explicada por se tratarem de "práticas de adultos e de uma sociedade que evita a confusão de seus sistemas sociais" (HERNÁNDEZ et al., 2007, p. 269, tradução nossa).

A característica dos jogos tradicionais indígenas, no que se refere à rede de comunicação motriz, assemelha-se aos jogos esportivos institucionalizados que, segundo Elloumi e Parlebas (2009), caracterizam-se pelo monopólio, estabilidade e equilíbrio.

No âmbito pedagógico, em específico no caso dos indígenas que inseriram os jogos tradicionais no conteúdo escolar, devemos atentar para essa questão, pois parece limitar-se a uma única possibilidade de rede de comunicação, a mesma imposta pela maioria dos esportes, ou seja, fixa, estável e simétrica. Segundo Lagardera e Lavega (2003),

[...] as consequências sobre as condutas motrizes do aluno podem ser tão extraordinárias como distintas, dependendo da rede de comunicações que se está promovendo nos jogos que são escolhidos. Nas situações de jogos com redes de comunicação exclusivas e estáveis é mais fácil que um jogador fique em evidência, de maneira que aquelas pessoas menos competentes para realizar as ações motrizes que se pedem são rapidamente identificadas pelo grupo, e inclusive às vezes ridicularizadas. Em troca, nos jogos com redes de 
comunicação instáveis ou ambivalentes, nos que tudo se modifica, nada se guarda, a estrutura social da prática vai contra esta marginalização, favorecendo o anonimato do resultado das ações motrizes dos jogadores menos capazes (LAGARDERA; LAVEGA, 2003, p.161 - tradução nossa).

Constatamos que tanto nos jogos tradicionais analisados, do grupo social indígena, como nos esportes institucionalizados não são contemplados determinados grupos de redes de comunicação motriz, sendo: rede de comunicação ambivalente, quando qualquer jogador pode atuar a todo o momento como companheiro e/ou adversário, caracterizando uma situação paradoxal; e rede de comunicação instável, em que os jogadores variam as relações de cooperação e oposição durante o transcorrer do jogo.

Analisando como estão caracterizados os jogos tradicionais indígenas em relação ao Sistema de Classificação (QUADRO 7), que parte da compreensão de qualquer situação motriz como um sistema, em que o jogador se relaciona com o entorno físico e com outros possíveis jogadores, podemos dizer que, quanto ao critério de interação com outros participantes no grupo social indígena, há um equilíbrio entre as situações psicomotrizes e sociomotrizes, sendo metade dos jogos pertencente a uma situação e metade pertencente à outra. Ao analisar detalhadamente a interação presente nos jogos sociomotores identificamos que há um predomínio sociomotor de cooperação.

Quadro 7 - Classificação dos jogos tradicionais do grupo social indígena em relação ao Sistema de Classificação

\begin{tabular}{|c|c|c|c|}
\hline & CAI & $\begin{array}{c}\text { PERCENTUAL } \\
\text { DE } \\
\text { OCORRÊNCIA }\end{array}$ & NOME DO JOGO \\
\hline $\begin{array}{c}\text { Situação } \\
\text { psicomotriz }\end{array}$ & $\begin{array}{l}\text { Psicomotor em meio } \\
\text { domesticado }\end{array}$ & $50 \%$ & $\begin{array}{ll}\text { - } & \text { Arremesso de lança } \\
\text { - } & \text { Bodoque } \\
\text { - } & \text { Arco e flecha } \\
\text { - Jogo da vareta de } \\
\text { bambu }\end{array}$ \\
\hline
\end{tabular}




\begin{tabular}{|c|c|c|c|}
\hline \multirow{3}{*}{$\begin{array}{l}\text { Situação } \\
\text { sociomotriz }\end{array}$} & $\begin{array}{l}\text { Cooperação em meio } \\
\text { domesticado }\end{array}$ & $25 \%$ & $\begin{array}{l}\text { - } \text { Corrida da tora } \\
\text { - Peteca }\end{array}$ \\
\hline & $\begin{array}{l}\text { Cooperação - oposição } \\
\text { em meio domesticado }\end{array}$ & $12,5 \%$ & - Cabo de guerra \\
\hline & $\begin{array}{l}\text { Oposição em meio } \\
\text { domesticado }\end{array}$ & $12,5 \%$ & - Lutas corporais \\
\hline
\end{tabular}

Se tratando do critério, de relação do jogador com o entorno físico, encontramos todos os jogos indígenas sendo realizados em um meio físico estável, conhecido do praticante, em que a leitura que ele realiza do meio é nula, pois este é amplamente conhecido pelo praticante.

Assim, relacionando os dois critérios, encontramos no grupo social indígena quatro das oito categorias do Sistema de Classificação proposto por Parlebas (2001), predominando jogos pertencentes à categoria psicomotora em meio domesticado ( $\underline{\mathbf{C A I}})$. Essa predominância nos jogos indígenas de jogos sem interação motriz com outros participantes é semelhante às interações que ocorrem na sociedade atual, a qual, segundo Giovanni (2005, p.147), tem como um de seus traços mais marcantes "a individualização dos seus agentes sociais". Ainda segundo este autor, "o individualismo tem sua medida social na ideia da performance, do desempenho, que não é apenas exigido de todos, mas também é almejado por todos" (GIOVANNI, 2005, p.147).

Em relação ao modo como os jogos são finalizados, no grupo social indígena encontramos $100 \%$ dos jogos sendo finalizados com o cumprimento da tarefa estabelecida pelo jogo. Fica evidente nesse grupo social a priorização em cumprir a tarefa do jogo, não sendo seu foco principal o resultado final. Já nos esportes de alto rendimento, como futebol, basquetebol, handebol e futsal, a finalização dos jogos é diferente, em que o importante é o resultado final da partida, que, geralmente, é finalizada por tempo limite. Como as regras das modalidades esportivas sofrem 
modificações para uma "adequação midiática" (PILATTI, 2002, p. 68), e nestas incluise o modo de finalização do jogo, percebemos o quanto as práticas sofrem influência e são transformadas para uma adequação à indústria do entretenimento (PILATTI, 2002).

Em relação ao estado em que se encontram os jogos tradicionais do grupo social indígena, encontramos que $100 \%$ dos jogos estão em fase de progressão, ou seja, está aumentando a adesão de jogadores e a estimulação para a sua prática, como a inserção dos jogos no conteúdo escolar. Vale ressaltar a importância dessa progressão no sentido de preservar os jogos tradicionais como preservação da própria cultura. Uma importante organização mundial que se preocupa em proteger o patrimônio cultural intangível ou imaterial, no qual se encontram os jogos tradicionais, é a Organização das Nações Unidas para a Educação, Ciência e Cultura (UNESCO). Essa organização vem se esforçando para criar e consolidar instrumentos e mecanismos que conduzam o seu reconhecimento e a sua defesa, estabelecendo, assim, no ano de 1989, a Recomendação sobre a Salvaguarda da Cultura Tradicional e Popular, instrumento que fornece elementos para a identificação, a preservação e a continuidade dessa forma de patrimônio, assim como de sua disseminação. Mais recentemente, no ano de 2003, foi organizada a Convenção para a Salvaguarda do Património Cultural Imaterial para salvaguardar e assegura o respeito pelo patrimônio cultural imaterial dentro das comunidades, grupos e indivíduos em causa; sensibilizar, em níveis local, nacional e internacional, a importância do patrimônio cultural imaterial, e de garantir sua apreciação (UNESCO). Também no sentido de valorizar, resgatar e preservar os jogos tradicionais, que no Brasil vêm sendo realizados os Jogos dos Povos Indígenas e o Evento das Manifestações Esportivas Indígenas do Guarita. 
Caracterizados os elementos da lógica interna e lógica externa (contexto) dos jogos tradicionais do grupo social indígena, destacamos que foram encontradas características peculiares destes, em relação aos esportes institucionalizados, no caso:

- as instituições que organizam os jogos tradicionais do grupo social indígena são instituições não esportivas;

- a zona da localidade onde é praticada a maioria dos jogos tradicionais realizados no evento é o campo de futebol da comunidade, adaptado para os diferentes jogos;

- o material da maioria dos jogos tradicionais do grupo social indígena é procedente do meio natural e elaborado artesanalmente;

- os jogos tradicionais realizados na escola são praticados por ambos os sexos;

- são jogos tradicionais em que atuam pessoas de diferentes idades e em uma ampla faixa etária;

- são jogos tradicionais que se encontram em fase de progressão.

\section{Considerações Finais}

Os jogos tradicionais são compreendidos nesse estudo como uma manifestação cultural detentora de características do entorno onde é produzido e de sua vida cotidiana. Carrega consigo a história e conhecimentos consolidados ao longo de gerações, que são transmitidos, geralmente, pela oralidade. Sobre esse tema, encontramos que no Brasil há pouca produção do conhecimento que aborde os jogos tradicionais. É nesse espaço que a pesquisa "Diagnóstico dos Jogos Tradicionais do Campo e da Cidade no Estado do Rio Grande do Sul”, realizada pelo GPELF no ano de 2010, ganha relevância. Essa pesquisa foi objeto do presente estudo, o qual analisou 
elementos da lógica interna e do contexto dos Jogos Tradicionais do grupo social indígena no Estado do Rio Grande do Sul, a partir dos dados descritos na pesquisa do Diagnóstico.

Em linhas gerais, um dos aspectos marcantes foi a possibilidade de uma convivência intergeracional que esses jogos tradicionais indígenas proporcionam, sendo os jogos protagonizados por pessoas de diferentes idades e gerações. Outro aspecto importante se refere à estrutura estável, fixa e simétrica que esses jogos apresentam frente à relação entre jogadores. Essas características apontam para uma estrutura reduzida dos jogos tradicionais indígenas analisados, frente à riqueza que os jogos tradicionais possuem de improvisação das regras (número de jogadores, materiais, espaço de jogo) e diferentes maneiras de os protagonistas se relacionarem entre si, podendo ser, além da estrutura estável, estrutura instável e ambivalente.

Vale destacar a limitação que encontramos nesse estudo durante a análise e interpretação dos resultados. Não encontramos algumas informações em relação a alguns elementos dos jogos descritos na pesquisa do Diagnóstico, o que resultou em uma apresentação superficial de alguns elementos, pois não puderam ser mais bem explicitados e aprofundados.

\section{REFERÊNCIAS}

ALMEIDA, A. J. M. Esporte e cultura: análise acerca da esportivização de práticas corporais nos jogos dos povos indígenas. 2008. 131 f. Dissertação (Mestrado em Educação Física) - Universidade de Brasília, Brasília, 2008.

APPOLINÁRIO, F. Dicionário de metodologia científica: um guia para a produção do conhecimento científico. São Paulo: Atlas, 2009.

ASOCIACIÓN INTERNACIONAL DE JUEGOS Y DEPORTES TRADICIONALES. Estatutos de la Asociación Internacional de Juegos y Deportes Tradicionales. Aranda de Duero, 2009. 
CAILLOIS, R. Os jogos e os homens: a máscara e a vertigem. Lisboa: Cotovia, 1990.

DAMO, A. S. Produção e consumo de megaeventos esportivos - apontamentos em perspectiva antropológica. Comunicação, mídia e consumo, São Paulo, v. 8, n. 21, p. 67-92, mar. 2011.

DIAS, G.; MENDES, R. Jogos tradicionais portugueses - retrospectiva e tendências futuras. EXEDRA, Coimbra, n. 3, p. 51-58, 2010.

ELLOUMI, A.; PARLEBAS, P. Análise sociocultural dos jogos esportivos tradicionais tunisianos. Fitness Performance Journal, Rio de Janeiro, v. 8, n. 2, p. 136-145, mar./abr. 2009.

FUNASA. Fundação Nacional de Saúde. Política Nacional de Atenção à Saúde dos Povos Indígenas. Sistema de Informações da Atenção à Saúde Indígena - Siasi. 2002. Disponível em: http://bvsms.saude.gov.br/bvs/publicacoes/politica saude indigena.pdf Acesso em: 21 jan. 2015.

FUNDERGS - FUNDAÇÃO DE ESPORTE E LAZER DO RIO GRANDE DO SUL. Jogos dos Povos Indígenas do RS: regulamento geral. 2014. Disponível em: < http://www.fundergs.rs.gov.br/conteudo/1009/jogos-dos-povos-indigenas $>$. Acesso em: 19 mar. 2015.

GIOVANNI, G. Di. Mercantilização das práticas corporais: o esporte na sociedade de consumo de massa. Revista Gestão Industrial, Ponta Grossa, v. 1, n.1, p. 146-154, 2005.

HERNÁNDEZ, J. et al. Catálogo de los deportes y juegos motores tradicionales canarios de adultos. Barcelona: INDE, 2007. 335 p.

HUIZINGA, J. Homo Ludens: o jogo como elemento da cultura. São Paulo: Perspectiva, 2008.

LAGARDERA, F.; LAVEGA, P. Introducción a la Praxiología Motriz. Barcelona: Paidotribo, 2003.

LAVEGA, P. Educar las conductas motrices: un desafío para la educación física del siglo XXI. SIMPOSIUM INTERNACIONAL, 5: Educación Física, Deporte y Turismo Activo, 2004. Ponencias. Las Palmas de Gran Canaria: Asociación Científico Cultural de Investigación y Docencia en Actividad Física y Deportes, 2004.

. El juego y la tradición en la educación de valores. Educación Social, Barcelona, n.33, p. 54-72, 2006 a.

. Los juegos y deportes tradicionales en Cataluña. In: LAVEGA, P. (Ed.). Juegos Tradicionales y Sociedade en Europa. Barcelona: Asociación Europea de Juegos y Deportes Tradicionales, 2006b. 
Classificação dos jogos, esportes e as práticas motrizes. In: RIBAS, J. F. M. (Org.). Jogos e esportes: fundamentos e reflexões da praxiologia motriz. Santa Maria: UFSM, 2008.

. et al. Os jogos tradicionais no mundo: associações e possibilidades. Licere, Belo Horizonte, v.14, n.2, jun. 2011.

MAESTRO, F. Los juegos y deportes tradicionais em Aragón. In: LAVEGA, P. (Ed.). Juegos Tradicionales y Sociedade en Europa. Barcelona: Asociación Europea de Juegos y Deportes Tradicionales, 2006.

MARIN, E. C. et al. Jogos tradicionais no Estado do Rio Grande do Sul: manifestação pulsante e silenciada. Movimento, Porto Alegre, v. 18, n. 03, p. 73-94, jul/set. 2012.

2013.

.; RIBAS, J. F. M. (Org.). Jogo tradicional e cultura. Santa Maria: UFSM,

PARLEBAS, P. Juegos, deporte y sociedad. Léxico de praxiología motriz. Institut National du Sport et de l'Éducation Physique. Barcelona: Paidotribo, 2001.

2003 .

Elementos de sociologia del deporte. Málaga: Instituto Andaluz del Deporte,

PILATTI, L. A. Guttmann e o tipo ideal do esporte moderno. In: PRONI, M. W.; LUCENA, R. F. (Org.). Esporte: história e sociedade. Campinas: Autores Associados, p. 63- 76, 2002.

PINTO, L. M. S. M.; GRANDO, B. S. (Org.). Brincar, jogar, viver: IX jogos dos povos indígenas. 2.ed. Brasília: Ideal, 2011. 258 p.

PRONI, M. W. Brohm e a organização capitalista do esporte. In: PRONI, M. W.; LUCENA, R. F. (Org.). Esporte: história e sociedade. Campinas: Autores Associados, p. 31- 62, 2002.

RIBAS, J. F. M. Grupo social Indígena. In: MARIN, E. C.; RIBAS, J. F. M. (Org.). Jogo tradicional e cultura. Santa Maria: UFSM, 2013.

RIO GRANDE DO SUL. Atlas socioeconômico do estado do Rio Grande do Sul. Porto Alegre: Secretaria da Coordenação e Planejamento do Estado do Rio Grande do Sul, 2002. Disponível em: http://www.seplag.rs.gov.br/atlas/atlas.asp?menu=555 . Acesso em: 21 de jan. 2015.

ROCHA, M. E. M. Consumo traz felicidade? A publicidade no centro da cultura. Comunicação, mídia e consumo, São Paulo, v. 8, n. 23, p. 161-179, nov. 2011.

SOARES, C. L. et al. Metodologia do Ensino de Educação Física. São Paulo: Cortez, 1992. 
SÁ-SILVA, J. R.; ALMEIDA, C. D. de; GUINDANI, J. F. Pesquisa documental: pistas teóricas e metodológicas. Revista Brasileira de História e Ciências Sociais, São Leopoldo, n. 1, p. 01-15, jul. 2009.

\section{Endereço dos Autores:}

Sabrine Damian Silva

Rua Bernardino Garcia, n²087/101

Santiago - RS - 97.700-000

Endereço Eletrônico: sabrinedamian@hotmail.com

João Francisco Magno Ribas

Universidade Federal de Santa Maria

Centro de Educação Física e Desportos

Avenida Roraima, $\mathrm{n}^{\circ} 1000$ - prédio 51 - Bairro Camobi

Santa Maria - RS - 97.105-900

Endereço Eletrônico: ribasjfm@hotmail.com 